\title{
Assistência de enfermagem à gestante HIV positivo durante o pré-natal: uma revisão integrativa
}

\author{
Nursing care to HIV-positive pregnant women during prenatal care: an integrative review \\ Asistencia de enfermería a embarazadas seropositivas durante la atención prenatal: una \\ revisión integradora
}

Heuder Henrique Frederico da Silva ${ }^{1}$, Wieclesio Suelber Silva dos Santos ${ }^{1 *}$, Fernanda da Mata Vasconcelos Silva². Gardênia Conceição Santos de Souza ${ }^{3}$.

\section{RESUMO}

Objetivo: Investigar na literatura sobre a assistência de enfermagem prestada à gestante portadora do vírus da imunodeficiência humana durante o pré-natal. Métodos: Trata-se de um estudo de revisão integrativa da literatura, com abordagem qualitativa realizada nas bases de dados Biblioteca Virtual de Saúde (BVS), Scientific Eletronic Library Online (SCIELO) e a PUBMED, a partir dos Descritores em Ciências Saúde (DeCS): "HIV", "Gestantes" e "Enfermagem" e os Medical Subject Headings (MeSH): "HIV", "Pregnant" and "Nursing". Os critérios de inclusão foram artigos originais publicados nos idiomas português e inglês, disponíveis na íntegra, que abordassem a temática no período de 2015 a 2020. Como critérios de exclusão, artigos duplicados nas bases de dados, incompletos e fora do período estipulado, sendo selecionados 13 estudos para compor a revisão. Resultados: Na assistência à gestante soropositivo, o enfermeiro executa inúmeras atividades, através do aconselhamento pré e pós-testes, realização das consultas de pré-natal, abrangendo a realização dos exames de rotina do pré-natal e acompanhamento do tratamento terapêutico com os antirretrovirais. Considerações finais: A assistência a gestante HIV positivo pode ocorrer nos três níveis de atenção à saúde, com objetivo de assegurar os cuidados a mulher e ao concepto durante a gestação, parto e puerpério.

Palavras-chave: HIV, Gestantes, Enfermagem.

\section{ABSTRACT}

Objective: To investigate in the literature about the nursing care provided to pregnant women with human immunodeficiency virus during prenatal period. Methods: This is an integrative literature review study, with a qualitative approach carried out in the databases Biblioteca Virtual de Saúde (BVS), Scientific Eletronic Library Online (SCIELO) and PUBMED, from the Descritores em Ciências Saúde (DeCS): "HIV", " Gestantes" e "Enfermagem" and the Medical Subject Headings (MeSH): "HIV", "Pregnant" and "Nursing". The inclusion criteria were original articles published in Portuguese and English, available in full, that addressed the theme in the period from 2015 to 2020. As exclusion criteria, duplicate articles in the databases, incomplete and outside the stipulated period, being selected 13 studies to make up the review. Results: In the care of HIV-positive pregnant women, the nurse performs numerous activities, through the pre and posttest counseling, conducting prenatal consultations, covering the prenatal routine tests and monitoring the therapeutic treatment with antiretroviral drugs. Final considerations: HIV positive pregnant women assistance can occur in the three levels of health care, aiming to ensure the care of the woman and the child during pregnancy, childbirth, and the puerperium.

Keywords: HIV, Pregnant, Nursing.

\section{RESUMEN}

Objetivo: Investigar la literatura sobre cuidados de enfermería concedidos a gestantes portadoras del virus de la inmunodeficiencia humana durante el prenatal. Métodos: Se trata de un estudio de revisión integradora de la literatura, con enfoque cualitativo realizado en las bases de datos Biblioteca Virtual en Salud (BVS), Biblioteca Electrónica Científica en Línea (SCIELO) y PUBMED, con base en los Descritores em Ciências Saúde (DeCS): "HIV", " Gestantes" e "Enfermagem" y los Medical Subject Headings (MeSH): "HIV", "Pregnant" and "Nursing". Los criterios de inclusión fueron artículos originales publicados en portugués e inglés, disponibles en su totalidad, que abordaran el tema de 2015 a 2020. Como criterios de exclusión, artículos duplicados en las bases de datos, incompletos y fuera del período estipulado, siendo seleccionados 13 estudios para componer la revisión. Resultados: En la asistencia a las embarazadas VIH-positivas, la enfermera realiza numerosas actividades, a través del asesoramiento pre y posprueba, realizando consultas prenatales, incluida la realización de exámenes prenatales de rutina y el seguimiento del tratamiento terapéutico con antirretrovirales. Consideraciones finales: La atención al gestante VIH positiva puede darse en los tres niveles de atención de la salud, con el objetivo de asegurar la atención a la mujer y al feto durante el embarazo, parto y puerperio.

Palabras clave: VIH, Mujeres embarazadas, Enfermería.

\footnotetext{
${ }^{1}$ Faculdade da Escada (FAESC), Escada - PE. *E-mail: suelbe-r@outlook.com

2 Universidade de Pernambuco (UPE), Recife - PE.

3 Universidade Federal de Pernambuco (UFPE), Recife - PE.
} 


\section{INTRODUÇÃO}

A Síndrome da Imunodeficiência Adquirida (AIDS) é uma doença crônica infecciosa e um dos maiores problemas mundiais de saúde. Essa patologia possui como agente causador o Vírus da Imunodeficiência Humana (HIV), um retrovírus que agride as células específicas do sistema imunológico, responsáveis por proteger o organismo de doenças deixando o indivíduo indefeso, por consequência, quanto menor estiver o nível dessas células maior o risco do indivíduo de desenvolver a AIDS, dessa forma, possuir o vírus HIV positivo não significa ter AIDS (BRASIL, 2017).

De acordo com Sales WB, et al. (2017), no Brasil, o primeiro caso de AIDS surgiu na década de 1980 na cidade de São Paulo, sendo as regiões metropolitanas de São Paulo e Rio de Janeiro as principais atingidas. A doença se alastrou imediatamente tornando-se um dos maiores problemas de saúde enfrentados pelo país, e desde então tem ganhado destaque devido a quantidade de casos que são diagnosticados todos os anos, além disso, em virtude da mortalidade e do impacto causado por essa doença (LIMA SS, et al., 2017).

A AIDS caracteriza-se por promover uma imunossupressão profunda no organismo, favorecendo o aparecimento de infecções oportunistas e tumores malignos, bem como a perda de peso e ainda a degeneração do sistema nervoso central (BRASIL, 2017). Os dados epidemiológicos do Ministério da Saúde apontam que no período de 1980 até junho de 2019 foram notificados 966.058 casos de AIDS no Brasil e nos últimos cinco anos, o país teve uma média de 39.000 novos casos de AIDS a cada ano (BRASIL, 2019).

A epidemia da infecção pelo HIV destaca-se pela magnitude e alcance dos danos que provoca na população no mundo e no Brasil. Em 2019 havia cerca de 38 milhões de pessoas vivendo com HIV no mundo, sendo 36,2 milhões de adultos e 1,7 milhões de crianças, menores de 15 anos (UNAIDS, 2020). De acordo com o boletim epidemiológico do Ministério da Saúde no período de 2007 a junho de 2019 no Brasil foram notificados pelo Sistema de Informação de Agravos de Notificação (SINAN) 300.496 casos de infecção pelo vírus (BRASIL, 2019).

Segundo Lima SS, et al. (2017), no início acreditava-se que a contaminação do vírus HIV ocorria apenas em um determinado grupo de risco, composto por homossexuais, dependentes químicos e prostitutas. Mas com a evolução da doença a contaminação passou a atingir outros segmentos populacionais. Atualmente, a contaminação passou a atingir os grupos heterossexuais principalmente as mulheres e esse processo ficou conhecido como feminilização da epidemia (LIMA SS, et al., 2017; SILVA NM, et al., 2016).

A epidemia da infecção pelo HIV vem evoluindo de forma crescente na população feminina em todo mundo. Com o aparecimento desse processo surgiu uma grande preocupação, devido a contaminação atingir principalmente as mulheres entre 20 e 34 anos, período esse em que as mesmas se encontram em fase reprodutiva e podem transmitir o vírus do HIV por meio da transmissão vertical materno-infantil (LIMA SS, et al., 2017). O período gestacional é considerado como um momento oportuno para detectar intercorrências, pois a mulher com suspeita de gravidez procura os serviços de saúde para iniciar o pré-natal (COSTA JFC, 2016).

Com relação ao HIV em gestantes, no período de 2000 até junho de 2019 estima-se que foram notificados cerca de 125.144 casos no Brasil. Segundo as pesquisas observaram-se que a maior prevalência de casos se encontra na região Sudeste com $38,1 \%$ das gestantes, seguida pelas regiões Sul $(30,0 \%)$, Nordeste $(17,7 \%)$, Norte $(8.3 \%)$ e o Centro-oeste (5,8\%) (BRASIL, 2019).

Geralmente, grande parcela das mulheres deseja a maternidade, porém no momento em que ocorre a gravidez surgem diversos questionamentos e sentimentos em relação ao desenvolvimento da gestação (CAMARGO RM, 2016). E com HIV tudo isso se agrava, pois mesmo com a evolução ainda não existe um tratamento curativo, além do que, é uma doença acompanhada por mitos e preconceitos morais e sociais, que afeta o psicológico, e também as relações familiares (BERTOLDO CF, 2014).

No decorrer do processo gestacional, recomenda-se a realização do teste anti-HIV para todas as mulheres, de preferência já na primeira consulta do pré-natal e a repetição da sorologia para HIV no começo do terceiro 
trimestre (BRASIL, 2013). O resultado positivo da sorologia pode ocasionar um grande impacto na vida das mulheres, visto que, remete à sentença de morte. As mulheres são tomadas por um sentimento de desespero, impotência, inconformismo, indignação, remorso e tristeza, sendo a maior preocupação, a transmissão do vírus para o bebê (BERTOLDO CF, 2014; SILVA NM, et al., 2016).

De acordo com Contim CLV, et al. (2015), a descoberta precoce da condição sorológica, durante o prénatal, é fundamental, visto que é provável estabelecer a quimioprofilaxia no momento adequado para prevenção da transmissão vertical. De acordo com o Ministério da Saúde, denomina-se transmissão vertical do HIV a situação em que a criança é infectada pelo vírus durante a gestação, parto ou amamentação pela mãe ou por outra pessoa com a sorologia positiva para o vírus.

Mesmo com os progressos, ainda existem fatorem que impedem as gestantes a não participarem das medidas de profilaxia no decorrer do pré-natal, parto, assim como no puerpério (LIMA SS, et al., 2017). Após o resultado positivo de infecção pelo vírus HIV durante a gestação, a mulher deve ser encaminhada para os serviços de referência, onde realizará o acompanhamento pré-natal de alto risco, porém também deve-se manter o seguimento do pré-natal na unidade básica de saúde (UBS) (SILVA NM, et al., 2016; BRASIL, 2016).

Nesse contexto, o enfermeiro, possui papel de destaque, uma vez que na maioria das situações conduz 0 atendimento inicial a gestante, principalmente nas unidades básicas de saúde durante o pré-natal, pois muitas vezes é o principal encarregado pelo aconselhamento (SILVA JM e SILVA F, 2018).

Dessa forma, considera-se o estudo relevante, devido ao número de casos expressivo de gestantes infectadas pelo HIV, principalmente se não forem prontamente orientadas e acompanhadas pelos profissionais de saúde, em virtude do risco de transmissão vertical materno-infantil. Deste modo, fica explicito a necessidade desta pesquisa para explorar mais profundamente sobre a importância do acompanhamento do pré-natal, visto que quando o vírus é diagnosticado precocemente tornar-se possível a conscientização e a colaboração nas estratégias de prevenção que certificam a redução da transmissão vertical da mãe para filho e a diminuição dos coeficientes de mortalidade materna.

Frente a este contexto, questiona-se: "De que forma ocorre a assistência de enfermagem à gestante portadora do vírus da imunodeficiência humana durante o pré-natal?". Dessa forma, o objetivo do estudo foi investigar na literatura sobre a assistência de enfermagem à gestante portadora do vírus da imunodeficiência humana durante o pré-natal.

\section{MÉTODOS}

Trata-se de um estudo de revisão de literatura, do tipo integrativa. O levantamento de dados foi realizado através das seguintes bases de dados: Biblioteca Virtual de Saúde (BVS), Scientific Eletronic Library Online (SCIELO) e a PUBMED, a partir dos Descritores em Ciências Saúde (DeCS): "HIV", "Gestantes" e "Enfermagem" e os Medical Subject Headings (MeSH): "HIV", "Pregnant" and "Nursing". Os descritores foram cruzados através do operador booleano "AND" para busca simultânea dos assuntos.

Com relação aos critérios de inclusão, durante a seleção, foram incluídos no estudo: artigos originais publicados no idioma português e inglês, que estavam disponíveis na íntegra, que abordassem a temática do estudo e indexados nas referidas bases de dados no período de 2015 a 2020. Como critérios de exclusão foram desconsiderados os artigos que não atendessem ao objetivo do estudo, as dissertações, monografias, teses, trabalhos de conclusão de curso (TCC), revisões de literatura, os artigos que não responderam à questão norteadora do estudo, artigos duplicados nas bases de dados, artigos fora do período estipulado e artigos incompletos.

Ao iniciar o rastreamento dos artigos para compor a amostra, cada base de dados foi explorada separadamente pelo cruzamento dos descritores. Por meio deste método de busca, foram encontrados 127 artigos, organizados em um fluxograma através do diagrama de fluxo PRISMA, adaptado segundo as recomendações de GALVÃO TF, et al. (2015). Desta forma, 18 artigos foram selecionados para leitura na integra, sendo incluídos apenas 13, para compor a revisão integrativa (Figura 1). 
Figura 1 - Fluxograma de cruzamentos, resultados das buscas nas bases de dados e os motivos de exclusão, adaptados no diagrama de fluxo PRISMA.

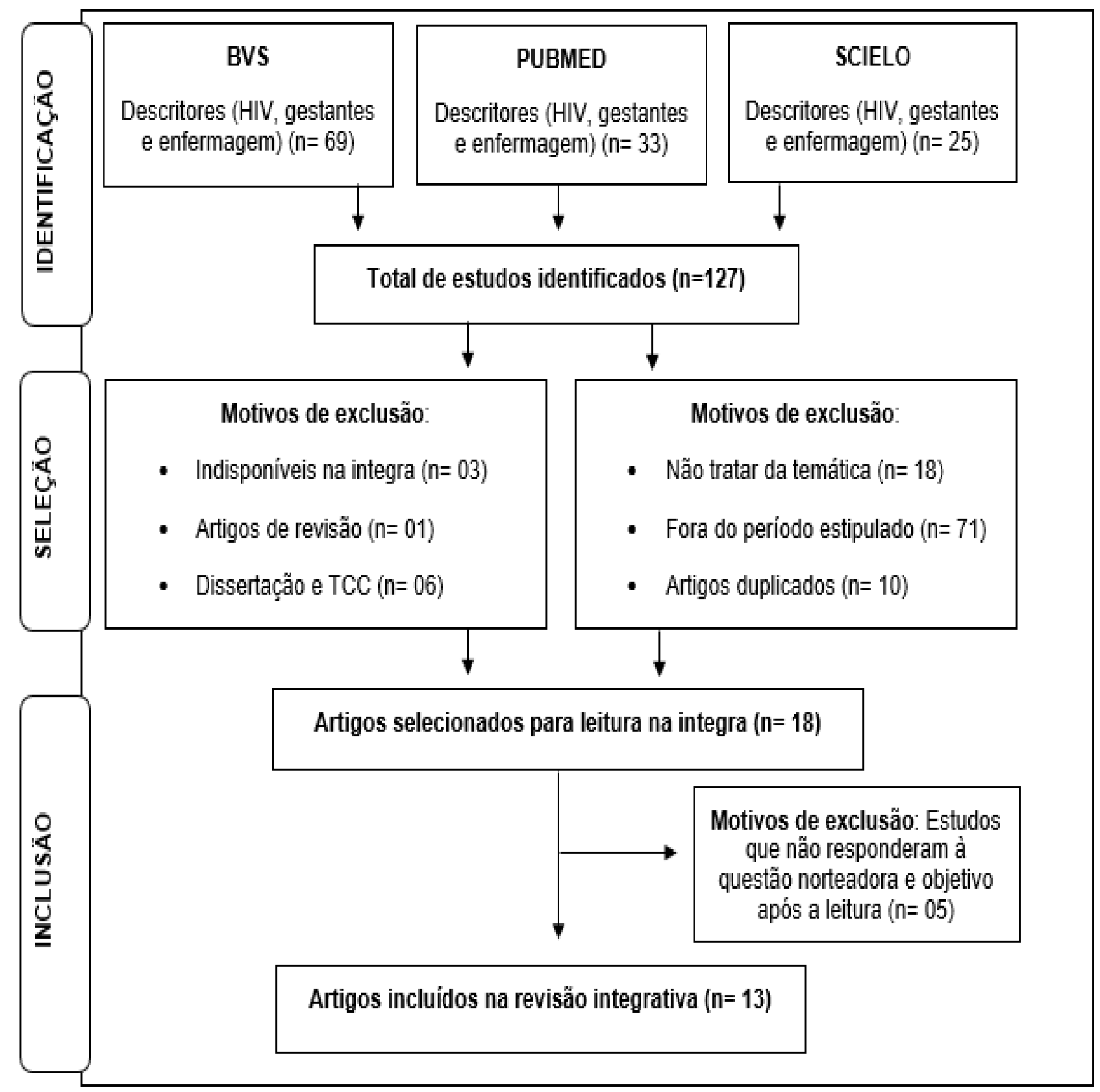

Fonte: Silva HHF, et al., 2021.

Após leitura e releitura dos artigos selecionados, foi realizada uma categorização em recortes temáticos, com o intuito de descrever e classificar os resultados, evidenciando o conhecimento produzido sobre o tema proposto. Por ter como referência bases públicas, não foi preciso a submissão ao Comitê de Ética e Pesquisa. Porém, o estudo respeita todos os preceitos éticos estabelecidos na resolução número 466/2012 do Conselho Nacional de Saúde (BRASIL, 2013).

\section{RESULTADOS E DISCUSSÃO}

Após a análise obteve-se como amostra final 13 estudos que se encaixaram nos critérios de inclusão da pesquisa, atenderam a pergunta norteadora e o objetivo determinado, no qual foi possível estabelecer as informações agrupadas na (Quadro 1). 
Quadro 1- Distribuição dos artigos incluídos na revisão de acordo com o título, autor, ano de publicação, objetivo, tipo de estudo e os resultados.

\begin{tabular}{|c|c|c|c|c|}
\hline Título & $\begin{array}{l}\text { Autor / ano de } \\
\text { publicacão }\end{array}$ & Objetivo & Tipo de estudo & Resultados \\
\hline $\begin{array}{l}\text { Implantação dos testes } \\
\text { rápidos para sífilis e HIV na } \\
\text { rotina do pré-natal em } \\
\text { Fortaleza-Ceará. }\end{array}$ & $\begin{array}{l}\text { LOPES ACMU, et al., } \\
2015 .\end{array}$ & $\begin{array}{l}\text { Descrever a implantação dos Testes Rápidos (TR) } \\
\text { de sífilis e HIV na rotina do pré-natal em unidades } \\
\text { primárias de saúde de Fortaleza, Ceará. }\end{array}$ & $\begin{array}{l}\text { Estudo descritivo com } \\
\text { abordagem quantitativa. }\end{array}$ & $\begin{array}{l}\text { O ministério da saúde preconiza que a primeira consulta pré- } \\
\text { natal deve ser realizada pelo enfermeiro e os Testes rápidos } \\
\text { devem ser oferecidos e concretizados nesse momento. }\end{array}$ \\
\hline $\begin{array}{l}\text { Panorama epidemiológico do } \\
\text { HIV/aids em gestantes de um } \\
\text { estado do Nordeste } \\
\text { brasileiro. }\end{array}$ & $\begin{array}{l}\text { SILVA CM, et al., } \\
2018 .\end{array}$ & $\begin{array}{l}\text { Conhecer as características epidemiológicas da } \\
\text { infecção pelo } \\
\text { HIV em gestantes. }\end{array}$ & $\begin{array}{l}\text { Estudo descritivo com } \\
\text { abordagem quantitativa. }\end{array}$ & $\begin{array}{l}\text { O enfermeiro exerce um papel fundamental como educador/ } \\
\text { facilitador durante o pré-natal, no qual tem o compromisso de } \\
\text { utilizar estratégias de educação em saúde, na tentativa de } \\
\text { mudanças de comportamento de risco; além disso, o } \\
\text { enfermeiro também possui um papel fundamental no que se } \\
\text { refere ao planejamento familiar, visto que é este quem realiza } \\
\text { a anamnese, o exame físico e ginecológico, investiga as } \\
\text { queixas atuais, metas reprodutivas e conhecimento sobre } \\
\text { métodos anticoncepcionais. }\end{array}$ \\
\hline $\begin{array}{l}\text { Análise espacial da infecção } \\
\text { pelo vírus r da } \\
\text { imunodeficiência humana } \\
\text { entre gestantes. }\end{array}$ & $\begin{array}{l}\text { HOLANDA ER, et al., } \\
2015 .\end{array}$ & $\begin{array}{l}\text { Analisar a distribuição espacial dos casos } \\
\text { notificados de gestantes infectadas pelo vírus da } \\
\text { imunodeficiência humana e identificar as áreas } \\
\text { urbanas de maior vulnerabilidade social para a } \\
\text { ocorrência da infecção entre gestantes. }\end{array}$ & Estudo ecológico. & $\begin{array}{l}\text { Por atuar diretamente na área de saúde materno-infantil, a } \\
\text { Enfermagem está envolvida com tais aspectos e deve } \\
\text { participar, juntamente com a equipe de saúde, da busca por } \\
\text { soluçóos para o enfrentamento dos determinantes sociais em } \\
\text { saúde, relacionados ao adoecimento por HIV/Aids. }\end{array}$ \\
\hline $\begin{array}{l}\text { Percepção da maternidade } \\
\text { pela gestante que vive com } \\
\text { HIV. }\end{array}$ & $\begin{array}{l}\text { SPINDOLA T, et al., } \\
2015 \text {. }\end{array}$ & $\begin{array}{l}\text { Identificar a percepção das gestantes que vivem } \\
\text { com o HIV sobre a maternidade e conhecer as } \\
\text { expectativas e os sentimentos vivenciados por } \\
\text { essas mulheres. }\end{array}$ & $\begin{array}{l}\text { Estudo descritivo e } \\
\text { abordagem qualitativa. }\end{array}$ & $\begin{array}{l}\text { A enfermagem, integrante da equipe multiprofissional que } \\
\text { assiste gestantes que vivem com o HIV, tem papel } \\
\text { preponderante na orientação para a saúde das mulheres e } \\
\text { aconselhamento para adesão das recomendações quanto à } \\
\text { profilaxia da transmissão vertical. }\end{array}$ \\
\hline $\begin{array}{l}\text { Estratégias para a adesão ao } \\
\text { tratamento de gestantes } \\
\text { soropositivas ao vírus da } \\
\text { imunodeficiência humana. }\end{array}$ & $\begin{array}{l}\text { PEREIRA FW, et al., } \\
2015 .\end{array}$ & $\begin{array}{l}\text { Identificar as estratégias que os profissionais } \\
\text { utilizam para auxiliar na adesão ao tratamento de } \\
\text { gestantes soropositivas para o Vírus da } \\
\text { Imunodeficiência Humana. }\end{array}$ & $\begin{array}{l}\text { Pesquisa exploratória, } \\
\text { descritiva de caráter } \\
\text { qualitativo. }\end{array}$ & $\begin{array}{l}\text { Os resultados apontaram como estratégias para adesão ao } \\
\text { tratamento de gestantes portadoras do HIV ações de } \\
\text { acolhimento, visando a inclusão dessas gestantes no serviço } \\
\text { e a aproximação com a equipe; a realização de atividades } \\
\text { grupais e a a busca ativa das faltosas, respeitando sua } \\
\text { autonomia e preservando seu sigilo. }\end{array}$ \\
\hline $\begin{array}{l}\text { A construção do vínculo das } \\
\text { enfermeiras da estratégia de } \\
\text { saúde da família com as } \\
\text { gestantes HIV positivo. }\end{array}$ & $\begin{array}{c}\text { GUELBER FACP, et } \\
\text { al., } 2019 .\end{array}$ & $\begin{array}{l}\text { Conhecer a percepção das enfermeiras em relação } \\
\text { à construção do vínculo na assistência prestada na } \\
\text { Estratégia de Saúde da Família com as gestantes } \\
\text { HIV positivo. }\end{array}$ & Pesquisa qualitativa. & $\begin{array}{l}\text { Foi possível apreender que as enfermeiras mantêm o vínculo } \\
\text { após encaminhar a gestante HIV positivo ao serviço } \\
\text { especializado. Nesse cuidar interativo, a enfermeira } \\
\text { desenvolve açóes e comportamentos de cuidar e a gestante } \\
\text { contribui com o cuidado na medida em que se torna } \\
\text { responsável por ele em situações de educação em saúde. }\end{array}$ \\
\hline $\begin{array}{l}\text { Revelação diagnóstica para o } \\
\text { HIV no pré-natal: dificuldades } \\
\text { e estratégias de } \\
\text { enfrentamento das mulheres. }\end{array}$ & $\begin{array}{c}\text { FERNANDES PKRS, } \\
\text { et al., } 2017 .\end{array}$ & $\begin{array}{l}\text { Investigar como as mulheres vivenciam a } \\
\text { revelação diagnóstica de infecção pelo Vírus da } \\
\text { Imunodeficiência Humana (HIV) no pré-natal e } \\
\text { identificar as estratégias de enfrentamento para } \\
\text { lidar com a soropositividade. }\end{array}$ & $\begin{array}{l}\text { Estudo descritivo, com } \\
\text { abordagem qualitativa. }\end{array}$ & $\begin{array}{l}\text { O enfermeiro durante o atendimento à mulher HIV positivo } \\
\text { pode utilizar o aconselhamento como um momento } \\
\text { importante para a construção de um saber sobre o sujeito, o } \\
\text { qual este pode estar se questionando e refletindo para além } \\
\text { de sua doença. Dessa forma, o aconselhamento permite ao } \\
\text { enfermeiro compreender a subjetividade e singularidade de } \\
\text { cada um, constituindo-se em uma ferramenta de apoio } \\
\text { emocional. }\end{array}$ \\
\hline
\end{tabular}




\begin{tabular}{|c|c|c|c|c|}
\hline Título & $\begin{array}{l}\text { Autor / ano de } \\
\text { publicação }\end{array}$ & Objetivo & Tipo de estudo & Resultados \\
\hline $\begin{array}{l}\text { Gestantes e puérperas } \\
\text { soropositivas para o HIV e } \\
\text { suas interfaces de cuidado. }\end{array}$ & $\begin{array}{l}\text { RAHIM SH, et al., } \\
2017 .\end{array}$ & $\begin{array}{l}\text { Compreender a percepção de ser } \\
\text { gestante/puérpera soropositiva para o HIV. }\end{array}$ & $\begin{array}{l}\text { Estudo qualitativo, } \\
\text { descritivo-exploratório. }\end{array}$ & $\begin{array}{l}\text { A equipe de enfermagem tem um papel importante para a } \\
\text { promoção do autocuidado das mulheres HIV positivo, sendo } \\
\text { que o enfermeiro deve estar ativo na educação e prevenção } \\
\text { dessas mulheres em idade reprodutiva para diminuir o } \\
\text { número de soropositivas, bem como prevenir a transmissão } \\
\text { vertical. }\end{array}$ \\
\hline $\begin{array}{l}\text { Aconselhamento } \quad \text { em } \\
\text { HIV/aids e sífilis às gestantes } \\
\text { na atenção primária. }\end{array}$ & $\begin{array}{l}\text { SILVA AP, et al., } \\
2018 .\end{array}$ & $\begin{array}{l}\text { Analisar as representações dos profissionais da } \\
\text { Atenção Primária acerca do aconselhamento em } \\
\text { HIV/ÂIDS e sífilis às gestantes. }\end{array}$ & Estudo qualitativo. & $\begin{array}{l}\text { Os profissionais de saúde salientam a importância da } \\
\text { prevenção do HIV/AIDS e sífilis, o empoderamento das } \\
\text { gestantes no que se refere à sorologia dessas IST, a partir } \\
\text { das consultas de pré-natal, e reforçam os exames como, por } \\
\text { exemplo, o anti-HIV para a detecção do HIV e o VDRL para a } \\
\text { detecção da sífilis. }\end{array}$ \\
\hline $\begin{array}{l}\text { O conhecimento dos } \\
\text { profissionais de saúde na } \\
\text { profilaxia da transmissão } \\
\text { vertical do HIV em uma } \\
\text { maternidade } \\
\text { brasileira. }\end{array}$ & $\begin{array}{l}\text { BARBOSA BLFA, et } \\
\text { al., } 2015 .\end{array}$ & $\begin{array}{l}\text { Avaliar o conhecimento dos profissionais de saúde } \\
\text { que cuidam de gestantes HIV positivo, quanto as } \\
\text { medidas profiláticas do risco de transmissão } \\
\text { vertical do HIV. }\end{array}$ & Estudo transversal. & $\begin{array}{l}\text { Dos profissionais investigados } 76 \% \text { apresentaram } \\
\text { conhecimento inadequado sobre o teste anti-HIV nas } \\
\text { gestantes, } 80 \% \text { desconheciam com que idade gestacional } \\
\text { realiza-se a cesárea eletiva quando carga viral for superior a } \\
1000 \text { cópias/ml, } 66 \% \text { não sabiam a dose para ataque do AZT } \\
\text { e o tempo de no mínimo duas horas a ser utilizado antes do } \\
\text { parto, } 84 \% \text { não conheciam qual o método indicado para } \\
\text { inibição da lactação. }\end{array}$ \\
\hline $\begin{array}{l}\text { Vivência de mulheres } \\
\text { diagnosticadas com HIV/aids } \\
\text { durante a gestação. }\end{array}$ & $\begin{array}{l}\text { BRINGEL APV, et al., } \\
2015 .\end{array}$ & $\begin{array}{l}\text { Descrever como as mulheres diagnosticadas com } \\
\text { HIV durante o pré-natal vivenciam o diagnóstico e } \\
\text { a gestação. }\end{array}$ & $\begin{array}{l}\text { Pesquisa exploratório- } \\
\text { descritiva, qualitativa. }\end{array}$ & $\begin{array}{l}\text { O enfermeiro no acompanhamento das gestantes } \\
\text { soropositivas, almeja com suas ações fortalecer o vínculo } \\
\text { com a paciente, e promover um cuidado humanizado, integral } \\
\text { e ético. }\end{array}$ \\
\hline $\begin{array}{l}\text { Tendência e } \\
\text { espacial distribuição } \\
\text { infecciosas em gestantes no } \\
\text { estado do Paraná-Brasil. }\end{array}$ & $\begin{array}{l}\text { FALAVINA LP, et al., } \\
2019 .\end{array}$ & $\begin{array}{l}\text { Analisar a tendência e a distribuição espacial de } \\
\text { algumas doenças de notificação compulsória em } \\
\text { gestantes. }\end{array}$ & Estudo ecológico. & $\begin{array}{l}\text { O enfermeiro tem papel fundamental no atendimento à } \\
\text { gestante com atividades desde a consulta de Enfermagem, } \\
\text { solicitação de exames e testes rápidos, orientações e } \\
\text { acompanhamento no diagnóstico e tratamento precoce de } \\
\text { agravos infecciosos como a sífilis, o HIV e a toxoplasmose. }\end{array}$ \\
\hline $\begin{array}{l}\text { Influência da exposição e } \\
\text { transmissão vertical do HIV-1 } \\
\text { no desenvolvimento } \\
\text { neuropsicomotor em } \\
\text { crianças. }\end{array}$ & $\begin{array}{l}\text { PAMPLONA MCCA, } \\
\text { et al., } 2019 .\end{array}$ & $\begin{array}{l}\text { Avaliar como o serviço de saúde brasileiro contribui } \\
\text { para evitar que crianças sejam afetadas pela atual } \\
\text { epidemia de HIV-1 e seus desfechos clínicos das } \\
\text { crianças afetadas. }\end{array}$ & $\begin{array}{l}\text { Estudo prospectivo, caso- } \\
\text { controle. }\end{array}$ & $\begin{array}{l}\text { É dever do profissional de saúde, principalmente o enfermeiro } \\
\text { solicitar o teste rápido anti-HIV-1 na primeira consulta de pré- } \\
\text { natal, devendo o teste ser repetido durante o terceiro trimestre } \\
\text { da gestação. A não detecção da infecção pelo HIV-1 devido à } \\
\text { ausência do teste do HIV-1 durante o pré-natal é considerada } \\
\text { uma falha na prevenção e no tratamento precoce, o que pode } \\
\text { prejudicar os esforços de controle da transmissão vertical do } \\
\text { HIV-1. }\end{array}$ \\
\hline
\end{tabular}

Fonte: Silva HHF, et al., 2021. 
Pode-se afirmar que as Unidades Básicas de Saúde (UBS) são consideradas como a porta de entrada para o diagnóstico de Infecções Sexualmente Transmissíveis (IST) em gestantes no âmbito do Sistema Único de Saúde (SUS), tornando-se encarregados pela captação das gestantes para a consulta pré-natal e a realização dos testes rápidos. Nesse sentido, Silva AP, et al. (2018) mostram que as gestantes que não conseguiram acesso a assistência pré-natal, o diagnóstico pode ser realizado na sala de parto, através do teste rápido (SILVA AP, et al., 2018).

Em concordância a isso, o estudo de Araújo EC, et al. (2018), constataram sobre a importância do prénatal e a obrigação dos profissionais de saúde principalmente os enfermeiros com relação a solicitação do teste rápido na primeira consulta, no terceiro trimestre e também no momento da internação para o parto, no entanto, isso não está sendo realizado em alguns serviços de saúde.

O estudo de Pamplona MCCA, et al. (2019) e Araújo EC, et al. (2018), enfatizam que quando não ocorre a detecção do vírus durante o pré-natal por causa da falta do teste rápido é visto como uma falha que afeta as ações de controle da transmissão vertical do HIV. Desde 2002, o teste rápido do vírus HIV é executado na rotina de trabalho das maternidades brasileiras, essa atividade foi instituída através do projeto NascerMaternidades (LOPES ACMU, et al., 2016).

Em contrapartida, percebe-se no estudo de Barbosa BLFA, et al. (2015), que os achados vão de encontro ao exposto no relato acima, pois durante o pré-natal, é aconselhado solicitação de exames mais sensíveis como a contagem de carga viral e linfócitos TCD4+. Portanto, o teste rápido anti- HIV deve ser feito de preferência na ocasião que não houve nenhum outro exame ao longo do pré-natal.

Tomando por base esse contexto o estudo realizado por Holanda ER, et al. (2015), ressalta que a falta da assistência, o início tardio ou a má qualidade do pré-natal são fatores de risco para a transmissão vertical do HIV, pois induzirá ao diagnóstico tardio da infecção e afetará o estabelecimento das etapas de prevenção em momento adequado, reduzindo a eficácia das medidas preventivas. Portanto, a garantia da qualidade da assistência e o acompanhamento rigoroso durante o pré-natal podem minimizar os danos à saúde da mãe e do bebê.

Em concordância a isso Silva CM, et al. (2018b), também constataram em um estudo realizado no Piauí em uma maternidade estadual inúmeros problemas nos serviços de saúde na inclusão das precauções profiláticas, na qual, o contexto socioeconômico em que a gestante está inserida, assim como a escassez no processo assistencial, estabeleceram consideráveis dificuldades na participação das mulheres ao pré-natal e também ao tratamento. Entretanto, percebe-se que Spindola T, et al. (2015), assumem diferente perspectiva discordando do que foi constatado no relato acima, ao afirmar que as gestantes em sua maioria participam do tratamento e das consultas diante da possibilidade da transmissão vertical, com o objetivo de conhecer a doença e suas implicações, com a finalidade de contribuir para promoção da saúde.

Nesse contexto, de acordo com Falavina LP, et al. (2019), o enfermeiro possui um papel importante nas condutas necessárias frente às doenças infecciosas na gestação e também é capacitado para orientar sua equipe sobre as intervenções necessárias. Os profissionais da enfermagem estão envolvidos diretamente na assistência à saúde da mulher e da criança, por isso devem se envolver para procurar soluções para os determinantes sociais dos problemas de saúde relacionados ao HIV/AIDS.

Em concordância ao exposto Spindola T, et al. (2015), afirmam que o aumento da expectativa de vida e da qualidade das pessoas que vivem com HIV exige que profissionais de saúde, incluindo enfermeiros que realizam atividades de enfermagem nos três níveis de atenção à saúde, prestem cuidados especiais.

Os estudos de Lopes ACMU, et al. (2016) e Falavina LP, et al. (2019), destacam sobre o papel do enfermeiro no atendimento as gestantes HIV positivo, onde relatam que o Ministério da Saúde recomenda que os enfermeiros realizem a primeira consulta de pré-natal e durante $o$ atendimento realize solicitação e avaliação de testes rápidos, orientações e acompanhamento no diagnóstico e tratamento precoce. Portanto, o enfermeiro nesses casos é considerado como o profissional fundamental no processo, com isso fica visível a necessidade de o mesmo estar apto para vincular junto à gestante a necessária dedicação a profilaxia da infecção. 
Pereira FW, et al. (2015), enfatizam que o enfermeiro, normalmente é o profissional encarregado por liderar e sistematizar o processo de enfermagem no cuidado de indivíduos em diferentes situações. Porém, é necessário que ocorra uma articulação junto as diferentes áreas com o intuito de promover um cuidado integral, devido a impossibilidade de um único profissional conseguir realizar o cuidado de forma ampliada e adequado com as necessidades individuais e coletivas.

Um estudo realizado no Rio Grande do Sul mostra a importância do enfermeiro com relação aos cuidados com a mulher no período gravídico-puerperal (LOPES ACMU, et al., 2016). Enfatizando esses aspectos, Fernandes PKRS, et al. (2017) destacam sobre os profissionais de saúde e sua importância, principalmente os enfermeiros, que não proporcionam assistência a mulher somente durante o período gestacional, mas também no decorrer de todas as situações, caso a mulher vivencie momentos de fragilidades perante os desafios que surgirem após o resultado.

Nesse caso, o enfermeiro pode utilizar as medidas preconizadas pela Rede Cegonha para o monitoramento do HIV/AIDS no período gravídico-puerperal, o que pode garantir o teste rápido, para que essas gestantes possam ser diagnosticadas e tratadas o mais precocemente possível, contribuindo assim para reduzir a mortalidade materna e mudanças no coeficiente de transmissão vertical do HIV (SILVA CM, et al., 2018b). Lopes ACMU, et al. (2016) aponta que o enfermeiro é considerado primordial, na qual a enfermagem apresenta-se sendo a mais capacitada, para a realização da testagem rápida na atenção primária.

Em se tratando das necessidades com relação aos aspectos psicológicos e sociais das mulheres soropositivas, pode-se constatar no estudo de Rahim SH, et al., (2017) que o enfermeiro deve estar atento, ao fato do medo que as mulheres sentem em contaminar outras pessoas da família, além disso os conflitos mentais e as indagações implicadas sobre a concepção. Em concordância a isso, Rahim SH, et al., (2017) ainda afirmam em seu estudo sobre a importância da educação em saúde como forma de contestar sobre os mitos e o preconceito perante o diagnóstico do vírus HIV.

Nesse contexto, o enfermeiro é considerado como o profissional que desenvolve ações, possui habilidades fundamentais para desenvolver intervenções durante 0 atendimento, com o objetivo da mulher sentir-se confortável, construindo assim a confiança na equipe, apoiando a aceitação e construindo laços entre ambas as partes, e também para que cada um entendam suas responsabilidades com relação ao tratamento (PEREIRA FW, et al., 2015).

Os resultados do estudo de Pereira FW, et al. (2015) apontaram como estratégias desenvolvidas pelos profissionais de saúde incluindo os enfermeiros ações de acolhimento com intuito de incluir as gestantes no âmbito dos serviços de saúde e manter aproximação com a equipe, a prática de atividades grupais e a busca ativamente das gestantes que não participam das atividades, preservando a liberdade da mulher e sua confidência.

Com o objetivo de promover um cuidado humanizado, integral e ético, o enfermeiro na assistência as gestantes soropositivas, através das suas condutas procura assegurar uma relação com a paciente. Considerando-se que quando a paciente tem uma relação de segurança com o profissional de saúde é possível estabelecer uma evolução quanto ao entendimento da doença e a participação do tratamento, viabilizando assim maior aceitação por parte da mulher e o enfretamento da doença de forma positiva (BRINGEL APV, et al., 2015).

Em concordância ao que foi exposto acima, Fernandes PKRS, et al. (2017) destacam que o atendimento da enfermagem é considerado como um processo relevante, com a finalidade de entender cada indivíduo com suas particularidades, além disso, é visto como momento propício para que ocorra o estabelecimento de relações e troca de conhecimentos. Entretanto, em contrapartida ao exposto acima Silva AP, et al. (2018a) constataram que os profissionais relataram ausência da oferta de preparação e capacitação para melhorias de conhecimentos referentes à prática de aconselhamento durante a assistência a gestante.

Tomando por base esse contexto Guelber FACP, et al. (2019) constataram que os enfermeiros elaboram condutas e atitudes de cuidar em situações de educação em saúde. Os enfermeiros desempenham o papel 
de educadores e facilitadores no qual utilizam métodos que envolvem educação em saúde com o objetivo de realizar mudanças no comportamento que envolve riscos (SILVA CM, et al., 2018b).

Com relação ao autocuidado das gestantes HIV positivo Guelber FACP, et al. (2019) relatam que os enfermeiros devem repassar informações sobre a importância do uso do preservativo e sua ligação direta com o HIV. O enfermeiro necessita permanecer atuante na educação e prevenção das mulheres em idade fértil com o intuito de minimizar o número de casos de gestantes HIV positivo, assim como evitar a transmissão vertical (RAHIM SH, et al., 2017).

Em contrapartida, percebe-se que Silva AP, et al. (2018a) em seu estudo mostram que a falta de preparo técnico dos profissionais de saúde na solicitação de testes rápidos e exames mais sensíveis sem os devidos aconselhamentos e assistência psicossocial e também abordagem ineficaz do parceiro sexual pode levar à incapacidade e implementação ineficaz de medidas durante a assistência pré-natal, levando ao aumento de falhas no diagnóstico e tratamento, com isso, interferem consideravelmente na prevenção de riscos de complicações que podem ocorrer durante o período gestacional.

\section{CONSIDERAÇÕES FINAIS}

A assistência de enfermagem a gestante HIV positivo pode ocorrer nos três níveis de atenção à saúde, com objetivo de assegurar os cuidados a mulher e ao concepto durante a gestação, parto e puerpério. Foi possível identificar que o enfermeiro atua como educador em saúde, solicita e avalia o teste rápido e exames mais sensíveis do HIV, atua no aconselhamento pré e pós teste, cria estratégias que ajudam a gestante a enfrentar os temores e anseios que pode surgir diante do diagnóstico, realiza as consultas de pré-natal abrangendo a solicitação e avaliação dos exames de rotinas, garante que as mulheres recebam o tratamento apropriado com os antirretrovirais e também atua na prevenção da transmissão vertical. Dessa forma, foi evidenciado a importância do enfermeiro para identificação precoce do vírus HIV em gestantes, no tratamento e no controle da transmissão vertical, sendo, por muitas vezes o principal responsável pela identificação dessas gestantes e aconselhamento.

\section{REFERÊNCIAIS}

1. ARAUJO EC, et al. Avaliação do pré-natal quanto à detecção de sífilis e HIV em gestantes atendidas em uma área rural do estado do Pará, Brasil. Rev Pan-Amaz Saude, Ananindeua, 2018; 9(1): 33-39.

2. BARBOSA BLFA, et al. Conhecimento dos profissionais de saúde na prevenção da transmissão vertical do HIV em maternidade pública brasileira. Revista electrónica trimestral de Enfermaria, 2015; 14(3): 1-28.

3. BERTOLDO CF. Transmissão vertical do HIV no período gestacional. Monografia (Especialização em Atenção Básica em Saúde da Família). Universidade Federal de Minas Gerais, Uberaba, 2014; 37 p.

4. BRASIL. Conselho Nacional de Saúde. Resolução CNS no 466, de 12 de dezembro de 2012. Aprova diretrizes e normas regulamentadoras de pesquisas devolvendo seres humanos [Internet]. Diário Oficial da União. Brasília; v. 150, no 122, p. 59-62, 2013. Disponível: https://bit.ly/1mTMIS3. Acesso em: 10 dez 2020.

5. BRASIL. Ministério da Saúde. Departamento de doenças de condições crônicas e infecções sexualmente transmissíveis. Boletim epidemiológico HIV/AIDS 2019. 2019. Disponível em: http://www.aids.gov.br/ptbr/pub/2019/boletim-epidemiologico-de-hivaids-2019. Acesso em: 15 dez. 2020.

6. BRASIL. Ministério da Saúde. Secretária de Atenção à Saúde. Departamento de Atenção Básica. Atenção ao pré-

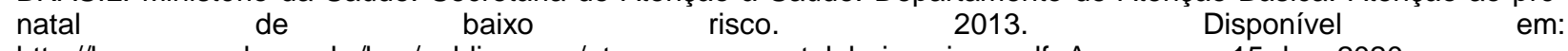
http://bvsms.saude.gov.br/bvs/publicacoes/atencao_pre_natal_baixo_risco.pdf. Acesso em: 15 dez. 2020.

7. BRASIL. Ministério da Saúde. Departamento de Vigilância, Prevenção e Controle das IST, do HIV/Aids e das Hepatites virais. 2017. Disponível em: http://www.aids.gov.br/pt-br. Acesso em: 15 dez. 2020.

8. BRASIL. Ministério da Saúde. Instituto Sírio-Libanês de ensino e pesquisa. Protocolos da atenção básica: Saúde das mulheres. 2016. Disponível em: http://bvsms.saude.gov.br/bvs/publicacoes/protocolos_atencao_basica_saude_mulheres.pdf. Acesso em: 15 dez. 2020.

9. BRINGEL APV, et al. Vivência de mulheres diagnosticadas com HIV/Aids durante a gestação. Ciência, Cuidado e Saúde, 2015; 14(2): 1043-1050.

10. CAMARGO RM. HIV no pré-natal: revisão integrativa da literatura. Monografia (Graduação em enfermagem). Universidade do Vale do Rio dos Sinos, Porto Alegre, 2016; 18 p.

11. CONTIM CLV, et al. Ser mãe e portadora do HIV: dualidade que permeia o risco da transmissão vertical. Revista Enfermagem Uerj, 2015; 23(3): 1-6.

12. COSTA JFC. Cuidados de enfermagem a gestantes de alto risco: Revisão integrativa. Monografia (Graduação em enfermagem). Universidade Federal Fluminense, Niteroi, 2016; $46 \mathrm{f}$. 
13. FALAVINA LP, et al. Tendência e distribuição espacial de doenças infecciosas em gestantes no estado do ParanáBrasil. Rev. Latino-Am. Enfermagem, 2019; 27: e3160.

14. FERNADES PKRS, et al. Revelação diagnóstica para o HIV no pré-natal: dificuldades e estratégias de enfrentamento das mulheres. Revista Enfermagem UERJ, 2017; 25: e12114.

15. GALVÃO TF, et al. Principais itens para relatar Revisões sistemáticas e Meta-análises: $A$ recomendação PRISMA. Epidemiol. Serv. Saúde, 2015; 24(2): 335-342.

16. GUELBER FACP, et al. A construção do vínculo das enfermeiras da estratégia de saúde da família com as gestantes HIV positivo. Revista online de pesquisa cuidado é enfermagem, 2019; 11(4): 976-983.

17. HOLANDA ER, et al. Análise espacial da infecção pelo vírus da imunodeficiência humana entre gestantes. Rev. LatinoAm. Enfermagem, 2015; 23(3): 441-449.

18. LIMA SS, et al. HIV na gestação: pré-natal, parto e puerpério. Ciência \& Saúde, 2017; 10(1): 1-6.

19. LOPES ACMU, et al. Implantação dos testes rápidos para sífilis e HIV na rotina do pré-natal em Fortaleza - Ceará. Rev. Bras. Enferm., 2016; 69(1): 62-66.

20. PAMPLONA MCCA, et al. Influence of exposure and vertical transmission of HIV-1 on the neuropsychomotor development in children. Rev. Soc. Bras. Med. Trop., Uberaba, 2019; 52: e-20180263.

21. PEREIRA FW, et al. Strategies for joining to the treatment for seropositive pregnant women to human immunodeficiency virus. Revista de Pesquisa: Cuidado é Fundamental Online, 2015; 7(3): 2796-2804.

22. RAHIM SH, et al. Gestantes e puérperas soropositivas para o HIV e suas interfaces de cuidado. Revista de enfermagem UFPE online, 2017; 11(10): 4056-64.

23. SALES WB, et al. Perfil epidemiológico do HIV/AIDS do estado do Paraná: estudo ecológico. Revista de Enfermagem e Atenção À Saúde, 2017; 6(1): 1-10.

24. SILVA JM, SILVA F. A enfermagem e a prevenção da transmissão vertical do HIV: uma revisão integrativa. Monografia (Graduação em enfermagem). Centro Universitário Univovafapi, Piaui, 2018.

25. SILVA NM, et al. Atuação da Enfermagem no cuidado da Gestante HIV positiva. Revista Cuidado em Enfermagem, 2016; 2(3): 46-55.

26. SILVA CM, et al. Panorama epidemiológico do HIV/AIDS em gestantes de um estado do Nordeste brasileiro. Rev. Bras. Enferm., 2018; 71(1): 568-576.

27. SILVA AP, et al. Aconselhamento em HIV/AIDS e sífilis às gestantes na atenção primária. Revista de enfermagem UFPE online., 2018; 12(7): 1962-9.

28. SPINDOLA T, et al. Percepção da maternidade por gestantes vivendo com HIV. Pesquisa e educação em enfermagem. Medellín, 2015; 33(3): 440-448.

29. UNAIDS. Estatísticas. 2020. Disponível em: https://unaids.org.br/estatisticas/. Acesso em: 15 dez. 2020. 